important that once factors have been developed, confirmatory data should be presented to validate the findings.

LIDDLE, P. F. (1987) The symptoms of chronic schizophrenia: a reexamination of the positive-negative dichotomy. British Journal of Psychiatry, 151, 145-151.

\& BARNES, T. R. E. (1990) Syndromes of chronic schizophrenia. British Journal of Psychiatry, 157, 558-561.

Mortimer, A. M., Lund, C. E. \& MCKenNA, P. J. (1990) The positive-negative dichotomy in schizophrenia. British Journal of Psychiatry, 157, 41-49.

Peralta, V., De Leon, J. \& Cuesta, M. J. (1992) Are there more than two syndromes in schizophrenia? A critique of the positivenegative dichotomy. British Journal of Psychiatry, 161, 335-343.

SONI, S. D., MAllik, A., ReED, P., et al (1992) Differences between chronic hospitalised schizophrenics and those living in the community: implications for clinical practice and research. Hospital and Community Psychiatry (in press)

SOM D. SONI

Sally Hollis

PAUL F. ReED

SHABIR MUSA

Hope Hospital

Salford

M6 $8 H D$

SIR: Peralta et al (Journal, September 1992, 161, 335-343) contribute to the developing consensus that factor analysis of schizophrenic symptoms yields at least three factors, consistent with the threesyndrome model (Liddle, 1987), but they conclude that a valid classification of symptoms has yet to be achieved. The evidence from a decade of scrutiny of the relationships between schizophrenic symptoms stimulated by Crow's concepts of type 1 and type 2 schizophrenia suggests that it is irrelevant to seek a classification such that each symptom belongs to a unique syndrome. The syndromes of schizophrenia are not discrete types of illness, but rather, groups of symptoms that coexist with each other more frequently than with those from other groups. Thus the symptoms of schizophrenia form a constellation of syndromes, all of which are related, but some of the relationships are closer than others.

The relationships revealed by factor analysis depend on the range of phenomena embraced by individual items and by the range of items entered into the analysis. Different choice of symptom rating scales will lead to emphasis on different aspects of the relationships between symptoms. This was demonstrated in my original study (Liddle, 1987), in which I analysed two different sets of symptom scores. The analysis of PSE scores produced a four-factor solution in which two factors reflected reality distortion. Delusions and hallucinations segregated into paranoic and Schneiderian groups. Some analyses will emphasise relationships that cross the boundaries within the three-syndrome model. For example, the relationship between formal thought disorder and some types of delusions is quite strong, so if the symptom rating scale combines all delusions into a single score (as in the Krawiecka scale), there will be overlap between items loading on the factors representing the disorganisation and reality distortion syndromes, as was found by Liddle \& Barnes (1990).

Insofar as relationships between symptoms reflect relationships in the pathophysiological processes that generate the symptoms (rather than mere artefacts of measurement procedure), examination of the pattern of relationships between symptoms might yield useful insights into the underlying pathophysiology. The three-syndrome model led me to propose three specific cerebral sites for the abnormalities associated with the three syndromes. These specific predictions were confirmed in a study of regional cerebral blood flow (Liddle et al, 1992). Furthermore, in accord with expectation, the specified sites were part of three overlapping patterns of disturbed function in multimodal association cortex. An analysis of the data using canonical correlation demonstrated the areas of overlap between the different syndromes (Friston et al, 1992). In particular, the left medial temporal lobe was implicated in all three syndromes. Thus, despite the clinical heterogeneity of schizophrenia, contemporary evidence reinforces Kraepelin's amalgamation of catatonia, hebephrenia and dementia paranoides to form a single disease.

LiddLe, P. F. (1987) The symptoms of schizophrenia: a reexamination of the positive-negative dichotomy. British Journal of Psychiatry, 151, 145-151.

\& BARNES, T. R. E. (1990) Syndromes of chronic schizophrenia. British Journal of Psychiatry, 157, 558-561.

-, Friston, K. J., Frith, C. D., et al (1992) Patterns of cerebra blood flow in schizophrenia. British Journal of Psychiatry, 160, 179-186.

Friston, K. J., Liddle, P. F., Frith, C. D., et al (1992) The left medial temporal region and schizophrenia: a PET study. Brain, $115,367-382$.

Hammersmith Hospital

Peter F. Liddle

Ducane Road

London W12 0HS

\section{Propofol and ECT}

SIR: We have been following with interest the recent correspondence in the Journal concerning the role of propofol in anaesthesia for ECT (Pippard, 1992; Haddad \& Benbow, 1992). Both Dr Pippard and Drs Haddad and Benbow warn against the use of propofol on the grounds that the well-demonstrated 
reduction in ECT-induced seizure duration with this agent (Dwyer et al, 1988) necessarily means that propofol causes a consequent reduction in the efficacy of this treatment. Although this rationale is consistent with widespread clinical wisdom, there has in fact been no scientific substantiation of a minimum necessary seizure length. If anything, recent studies indicate that seizure length is clearly not related to efficacy. For example, Sackeim et al (1987), in a study comparing seizure threshold doses of bilateral and unilateral ECT, found no difference in the mean individual seizure duration despite a significantly better response with the bilateral treatment.

In view of the lack of any data concerning this question, we recently reported a retrospective study reviewing the experience with propofol in a specialised mood disorders unit at Prince Henry Hospital, Sydney (Mitchell et al, 1991). Over a 30 month period, 66 patients with primary depression were treated with ECT. The study period spanned 15 months before and after the introduction of propofol into this hospital. Choice of anaesthetic induction agent was determined by the individual preference of the anaesthetist and not by diagnosis, age, or physical status of the patient. Either thiopentone or propofol was used. The 21-item Hamilton Rating Scale for Depression (HRSD) had been administered prospectively before and 1-2 weeks after ECT to 37 of these patients who were involved in other research projects. These ratings were made without knowledge of the anaesthetic agent used.

The ratio of the mean $\mathrm{mg} / \mathrm{kg}$ doses of thiopentone and propofol actually administered (2.01) was close to the published equipotency ratio of 1.61 . We replicated the previous reports of a reduced seizure duration with propofol, finding a mean of 18.1 with this agent compared with 24.7 with thiopentone $(P<0.01)$. Despite this reduction, we found a highly significant improvement in HRSD ratings in those patients given propofol (mean reduction from 28.2 to $7.5, P<0.01$ ), which was not significantly different to that observed with thiopentone as the anaesthetic agent. We did, however, observe a weak trend suggesting that patients receiving propofol required more treatments per course (13.0 v. 10.8; $P=0.18)$.

Although we are fully aware of the limitations of a retrospective study, our findings suggest that propofol may not, in fact, impair the efficiency of ECT. Prospective studies are necessary to answer the question definitively. As with many issues related to ECT, the discussion about propofol requires more data and less unsubstantiated polemic.

DWyer, R., MCCAUGheY, J., LAVERY, J., et al (1988) Comparison of propofol and methohexitone as anaesthetic agents for electroconvulsive therapy. Anaesthesia, 43, 459-462.
HAdDad, P. M. \& Benbow, S. M. (1992) Propofol and ECT. British Journal of Psychiatry, 161, 277-278.

Mrtchell, P., TORDA, T., HickIE, L., et al (1991) Propofol as an anaesthetic agent for ECT: effect on outcome and length of course. Australian and New Zealand Journal of Psychiatry, 25, 255-261.

PIPPard, J. (1992) Audit of electroconvulsive therapy in two National Health Service regions. British Journal of Psychiatry, 160, 621-637.

SACKem, H., Decina, P. \& KANzler, M. (1987) Effects of electrode placement on the efficacy of titrated, low-dose ECT. American Journal of Psychiatry. 144, 1449-1455.

\section{Philip Mitchell}

IAN HICKIE

THOMAS TORDA

Departments of Psychiatry and Anaesthetics

University of New South Wales

Prince Henry Hospital

Little Bay, NSW 2036, Australia

\section{Clozapine}

SIR: We were somewhat surprised by the recent letter concerning the prescribing of clozapine for treatment of psychosis in the community (Phelan et al, Journal, September 1992, 161, 425-426). Firstly, clozapine has only been used outside research settings in the UK. This is the commonest misconception that bedevils clozapine; that it is a new research drug. It is a licensed drug with known effectiveness which was demonstrated in ordinary psychiatric practice in the 1960 s and more recently by one of the most rigorous multicentre, placebo-controlled drug trials performed in the last decade (Kane et al, 1988). Indeed, trials of clozapine have all been performed on clinical samples, not specialised research cohorts. In particular, its efficacy has been documented in subgroups of seriously ill, long-stay in-patients. These patients, resistant to typical antipsychotics, are a massive burden on hospital services and a perpetual risk to themselves and others.

Secondly, the service implications of an 'almost full-time' nurse to monitor blood sampling, and liaise with patients, their families, doctors, and the laboratory would seem extremely cost-effective in comparison with the prolonged and frequent hospital admissions otherwise required, and should not such ill patients have high levels of input in any case? The use of clozapine in our catchment area has allowed at least one patient to be brought out of a private long-stay facility costing $£ 70,000$ per year. Of the 2000 patients on clozapine in the UK, 500 are maintained in the community without problems. The monitoring system is specifically designed to prevent fatalities, and the smooth running of clozapine prescribing is the precise function of the 